\title{
Avaliação de desempenho térmico nos Módulos Antárticos Emergenciais (Brasil)
}

\author{
MARTINS, Wagner Gomes ${ }^{1}$ \\ ALVAREZ, Cristina Engel de ${ }^{2}$ \\ 1Universidade Federal do Espírito Santo, Vitória. wgmartins.arq@gmail.com \\ 2Universidade Federal do Espírito Santo, Vitória. cristina.engel@ufes.br
}

\section{Resumo}

Os Módulos Antárticos Emergenciais - MAE, instalados na Península Keller, desde 2013 têm servido à continuidade das atividades desenvolvidas no local após o incêndio de parte da brasileira Estação Antártica Comandante Ferraz. Tendo-se em vista as condições climáticas extremas e a necessidade de se obter conforto térmico com o menor gasto energético e impacto ao meio-ambiente, avaliou-se o desempenho do conjunto edificado, particularmente quanto à sua capacidade de manter a temperatura interna estável e dentro de uma faixa de aceitação conforme as normas aplicáveis, considerando-se também o isolamento proporcionado pela envoltória. Através de medições de temperatura, com o tratamento dos dados coletados e a análise dos resultados, verificou-se que não houve correlação entre a temperatura externa e a interna, sendo possível inferir que a envoltória garante 0 isolamento do ambiente interno, apesar de identificados alguns problemas de estanqueidade, e/ou que o sistema de aquecimento é capaz de compensar as diferenças de temperatura. É possível que os resfriamentos observados e as diferenças de temperatura entre horas seguidas tenham sido provocados pelo comportamento em uso, com perda de calor pela abertura de portas, por exemplo, principalmente no período de verão, em que há uma maior quantidade e movimentação de usuários.

Palavras-Chave: Módulos Antárticos Emergenciais; Antártica; Desempenho Térmico; Avaliação PósOcupação.

\begin{abstract}
The Emergency Antarctic Modules - MAE have been serving to the continuity of the activities undertaken at the Keller Peninsula since 2013, after the fire that destroyed part of the Brazilian Comandante Ferraz Antarctic Station. Taking into account the climatic conditions, the thermal comfort needs, the energy consumption and the impact on the environment, the performance of the built complex was assessed particularly in terms of maintaining a stable internal temperature within an acceptance range according to the standards, also considering the insulation provided by the envelopment. Through measurements of temperature, the processing of the collected data and the analysis of the results, it was found that there was no correlation between the internal and the external temperatures, so that it is possible to infer that the envelope ensures the required insulation, despite some identified problems concerning the air tightness of the building, and/or that the heating system is able to compensate the differences of temperature. It is possible that the observed temperature drifts have been caused by the behavior in use, with heat loss by opening doors, for example, especially in the summer period, when there is a greater amount of users in the MAE.
\end{abstract}

Key-Words: Emergency Antarctic Modules; Antarctica; Thermal Performance; Post-Occupancy Evaluation. 


\section{Introdução}

Os brasileiros estão presentes na região austral desde o final do século XIX, tendo a Estação Antártica Comandante Ferraz - EACF sido instalada em 1984, na Península Keller (Figura 1), com a integração do Brasil como membro consultivo do Tratado Antártico, e seu consequente estabelecimento no panorama internacional, na mesma década (SOUZA et al., 2008).

Acompanhando o desenvolvimento das pesquisas e o crescimento do prestígio brasileiro, com o passar dos anos a Estação passou por ampliações e reformas até atingir aproximadamente $2500 \mathrm{~m}^{2}$ no corpo principal - além de módulos isolados de laboratórios - e capacidade para alojar até 65 pessoas no verão, dentre pesquisadores, militares, equipe de manutenção e visitantes (FANTICELE, 2011).

A atenção às condições de uso das edificações e ao seu desenvolvimento ordenado foi uma preocupação constante, especialmente a partir de 2001, com a confecção de amplos diagnósticos de sua estrutura física, bem como a elaboração do zoneamento ambiental de uso para a Península Keller e do Plano Diretor da Estação, além das constantes melhorias na sua infraestrutura (SOUZA et al., 2008).

Apesar de todos os esforços para gerir e manter o melhor funcionamento e integridade das edificações, após 28 anos apoiando a comunidade científica, em fevereiro de 2012, a Estação sofreu um incêndio, que destruiu o corpo principal de suas instalações (SECRETARIA DA COMISSÃO INTERMINISTERIAL PARA OS RECURSOS DO MAR - SECIRM, acesso em 12 ago. 2016).

Para apoiar a retirada dos escombros do incêndio e, principalmente, para garantir a continuidade das atividades científicas, foram instalados próximo ao local os denominados Módulos Antárticos Emergenciais - MAE (Figura 2), projetados para funcionarem como uma estação provisória e que estão em uso desde o início de 2013 (MECH, 2013).

Atendendo-se ao Termo de Referência da Marinha do Brasil (2012), os MAE foram planejados para alojar uma população de até 66 pessoas, ou seja, semelhante à da EACF, tendo uma área total para habitação e apoio de $454 \mathrm{~m}^{2}$, conforme a proposta da empresa Weatherhaven Canada Resources Limited - WCRL (2012), contratada para o fornecimento e instalação das unidades construídas.

Figura 1: Localização da Estação Antártica Comandante Ferraz - EACF.

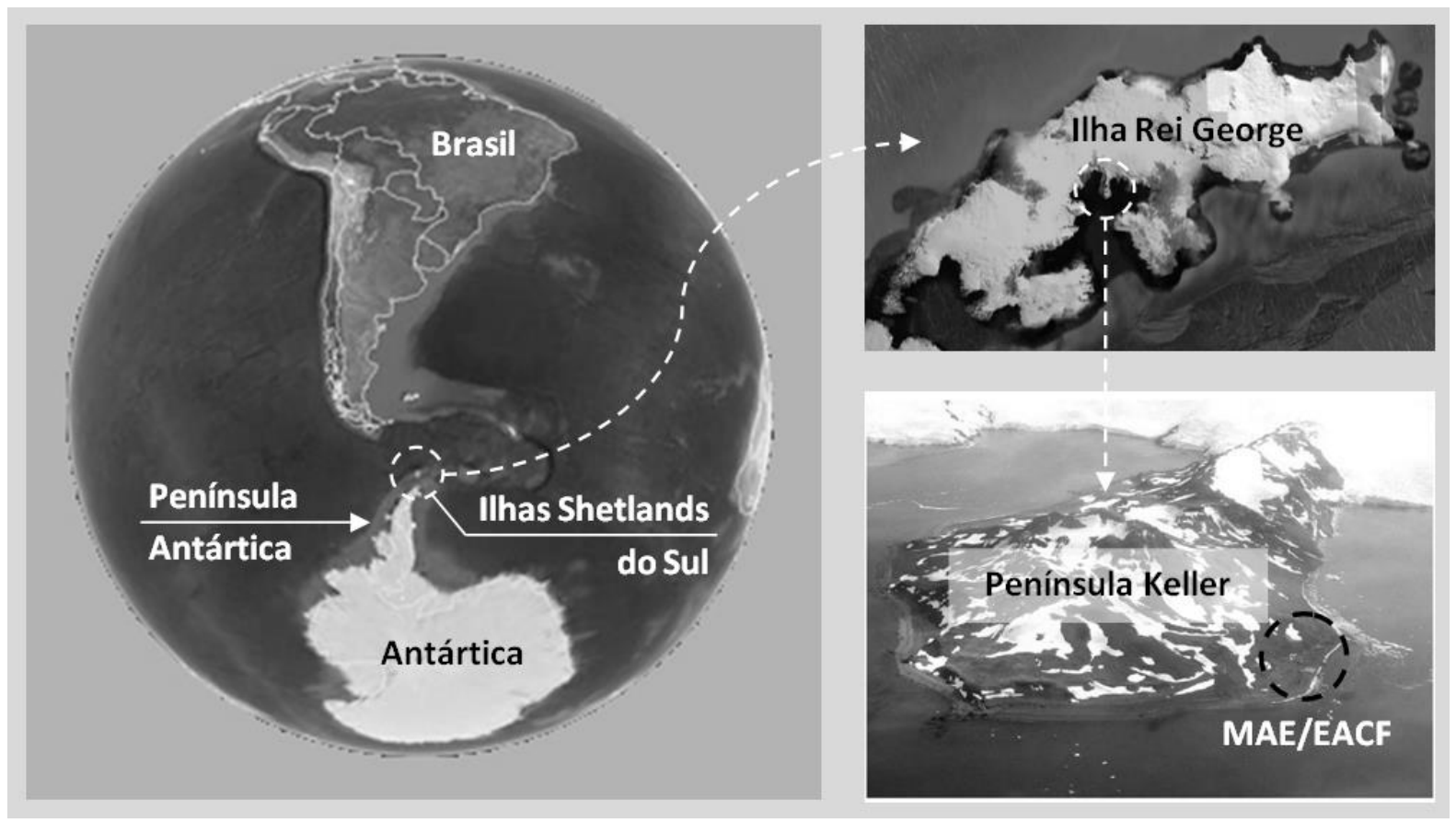

Fonte: adaptada de Autores (2013) 
Figura 2: Os Módulos Antárticos Emergenciais - MAE.

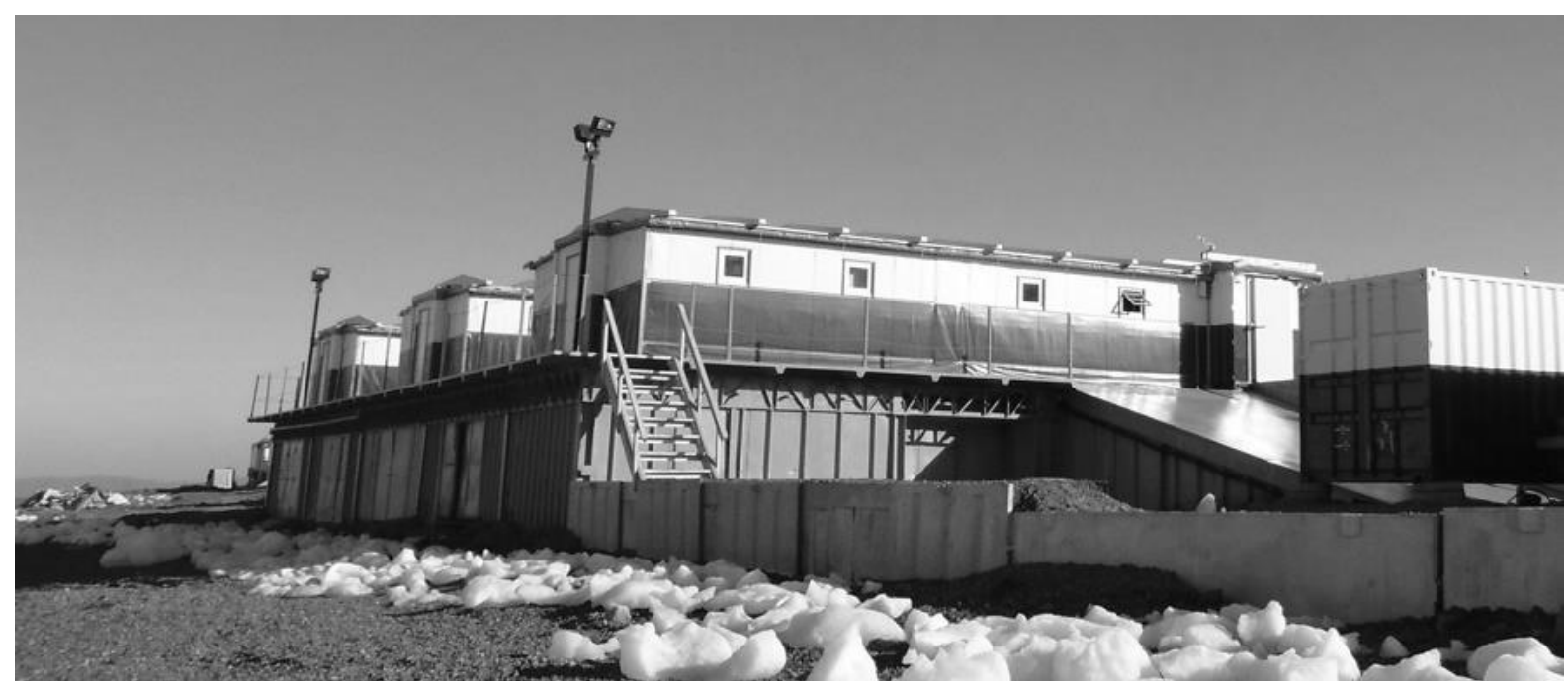

Fonte: acervo do Laboratório de Planejamento e Projetos, Universidade Federal do Espírito Santo.

Dentre os condicionantes para o projeto e instalação dos MAE, interessa para esta pesquisa especialmente aqueles referentes ao clima local e que nortearam a elaboração dos projetos dos MAE:

- Temperatura externa com média anual de $-2,8^{\circ} \mathrm{C}$, sendo que a mínima absoluta, registrada em 1991 , foi de $-28,5^{\circ} \mathrm{C}$, enquanto a máxima absoluta, registrada em 1998 , foi de $14,4^{\circ} \mathrm{C}$, até 2012 , quando se elaborou o Termo de Referência (UNIVERSIDADE FEDERAL DO RIO GRANDE DO SUL UFRGS, apud MARINHA DO BRASIL, 2012). Observa-se que, conforme os dados de climatologia de Ferraz disponibilizados pelo Centro de Previsão de Tempo e Estudos Climáticos, do Instituto Nacional de Pesquisas Espaciais - INPE (acesso em 06 abr. 2016), que abrange os anos de 1984 a 2013 , a média das médias anuais foi de $-1,8^{\circ} \mathrm{C}$; a média das mínimas foi de $-4,1^{\circ} \mathrm{C}$; e a média das máximas foi de $0,6^{\circ} \mathrm{C}$;

- Carga de neve com acúmulo de aproximadamente 1,5 m nos locais passíveis de instalação das unidades construídas e $50 \mathrm{~cm}$ para efeito de cálculo de coberturas planas (MARINHA DO BRASIL, 2012);

- Ventos fortes e constantes de até $200 \mathrm{~km} / \mathrm{h}$, para efeito de cálculo, sendo que a rajada de vento mais veloz já registrada na EACF foi de $178 \mathrm{~km} / \mathrm{h}$, em 2010 (MARINHA DO BRASIL, 2012); e

- Mudanças climáticas bruscas frequentes (MARINHA DO BRASIL, 2012).

Satisfazendo a questões logísticas, a solução técnica adotada incluiu módulos de rápida instalação, equipados de fábrica, e com formato de contêiner, sendo alguns expansíveis (Figura 3), facilitando-se o transporte e a montagem no local (MECH, 2013).

Entre os vários condicionantes de contrato, destaca-se que os MAE devem possuir vida útil mínima de cinco anos, com possibilidade de desmonte e relocação, atendendo às necessidades da SECIRM (MARINHA DO BRASIL, 2012).

Considerando-se as características extremas do meio em que a edificação está inserida, especialmente no que se refere às condições climáticas, há uma natural preocupação com a segurança, o bem-estar e, particularmente, o conforto térmico dos seus usuários.

Tendo-se em vista os preceitos do Protocolo ao Tratado Antártico sobre Proteção ao Meio Ambiente (SECRETARIA DO TRATADO ANTÁRTICO, apud MARINHA DO BRASIL, 2012), também é dada especial atenção ao impacto gerado ao meio-ambiente devido à queima de combustível fóssil realizada para se gerar a energia que é utilizada para o aquecimento do ambiente interno. 
Figura 3: Módulos expansíveis com formato de contêiner e equipados de fábrica.

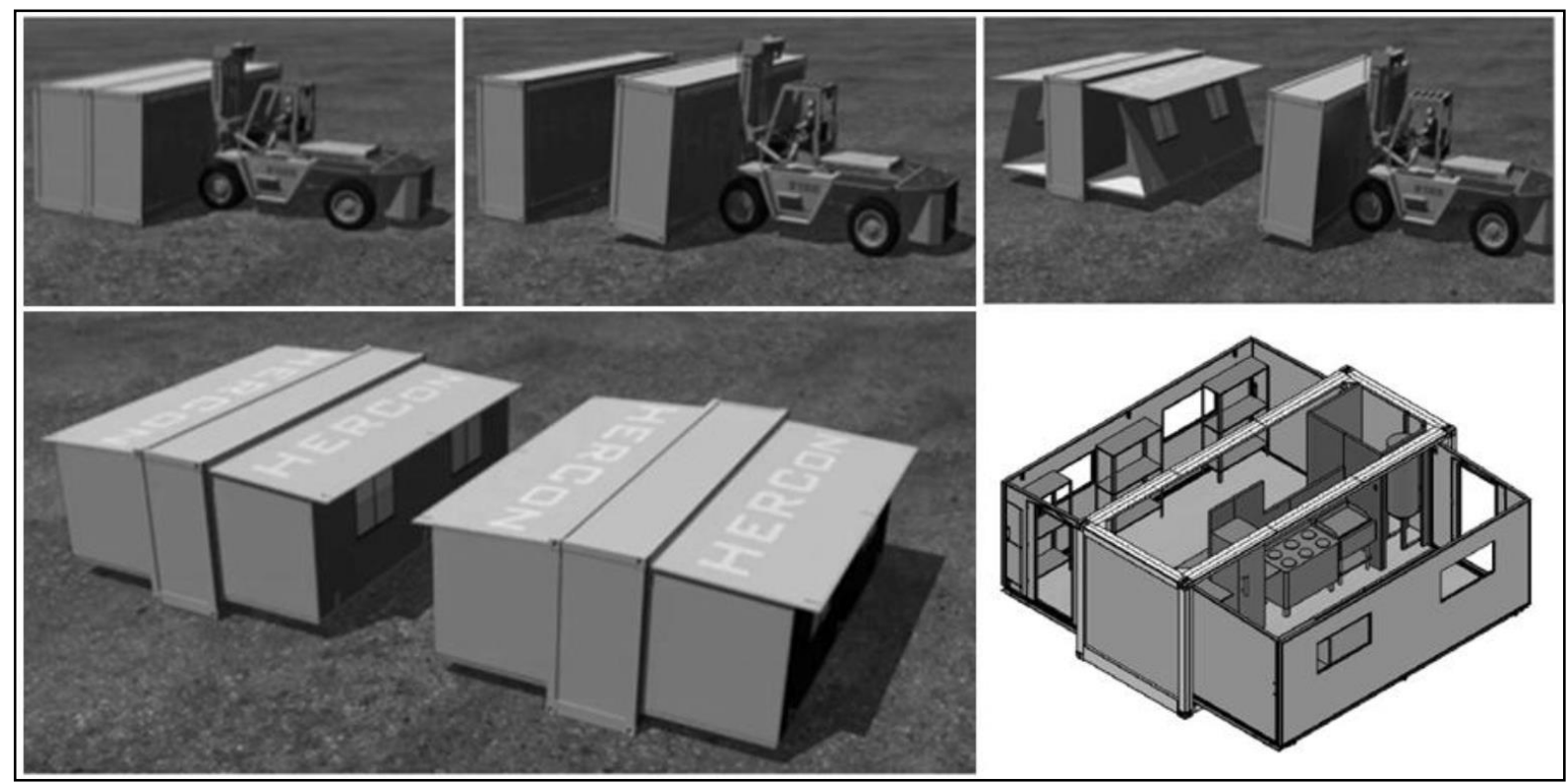

Fonte: elaborada a partir de imagens de WCRL (2012).

Outro aspecto relevante refere-se ao custo econômico, considerando principalmente a necessidade de transporte e de custo do combustível que alimenta o sistema energético.

Além disso, existe a preocupação em se avaliar o desempenho dos MAE pelo fato de que a técnica construtiva da edificação é diferenciada, sendo que os resultados da avaliação podem induzir a aprimoramentos, assim como novos projetos ou pesquisas correlatas.

Dessa forma, o objetivo do trabalho apresentado foi avaliar o desempenho térmico dos MAE, especialmente quanto à sua capacidade de manter a temperatura interna estável e dentro de uma faixa aceitável conforme as normas aplicáveis, considerando-se também o isolamento proporcionado pela envoltória, que a princípio deve garantir a preservação do calor interno.

\section{Métodos e Instrumentos}

Uma vez que a edificação avaliada já se encontra em fase de uso, foi definido que o trabalho se desenvolveria a partir das diretrizes determinadas pela metodologia de Avaliação Pós-Ocupação - APO do ambiente construído, que considera o ponto de vista técnico assim como aspectos de uso (ORNSTEIN e ROMERO, 1992; GUERRA-SANTIN e TWEED, 2015). Ressalta-se que essa metodologia já tinha sido utilizada para avaliação de edificações na EACF, mostrando-se adequada ao contexto (ALVAREZ et al., 2004). Destacam-se os resultados pioneiros obtidos por Fanticele (2011), que também adotou os procedimentos recomendados por Ornstein \& Romero (1992), com adaptações, tendo servido como importante referência para a pesquisa, considerando-se o meticuloso relato do processo de coleta, tratamento e análise dos dados, para avaliação de conforto térmico na antiga edificação principal da EACF.

A fim de se atingir o objetivo proposto, os procedimentos adotados foram divididos em quatro (04) etapas, apresentadas nos tópicos a seguir, em sequência. Observa-se que as etapas 1 e 3 serviram para o desenvolvimento das seguintes, sendo que os principais resultados foram obtidos nas etapas 2 e 4 .

\subsection{Levantamento de dados com escolha dos locais de medição interna e instalação dos equipamentos}

Seguindo-se as diretrizes da metodologia de APO, a princípio foram realizadas visitas exploratórias e levantamentos junto aos usuários, para se identificar eventuais problemas e aspectos relevantes a serem 
considerados na definição dos parâmetros de interferência, conforme apresentado em Autores (2014).

Também foram consultadas as normas aplicáveis, tendo-se adotado a ISO 7730 (2005) como referência principal para o trabalho, por ter sido desenvolvida em particular para edificações condicionadas artificialmente.

Para a amostragem da temperatura interior, foram selecionados quatro (04) ambientes de maior utilização e permanência dos ocupantes, em que a expectativa por conforto também é alta, apresentados em destaque na Figura 4.

Figura 4: Planta baixa esquemática dos Módulos Antárticos Emergenciais com destaque para os quatro (04) ambientes onde foram realizadas as medições de temperatura.

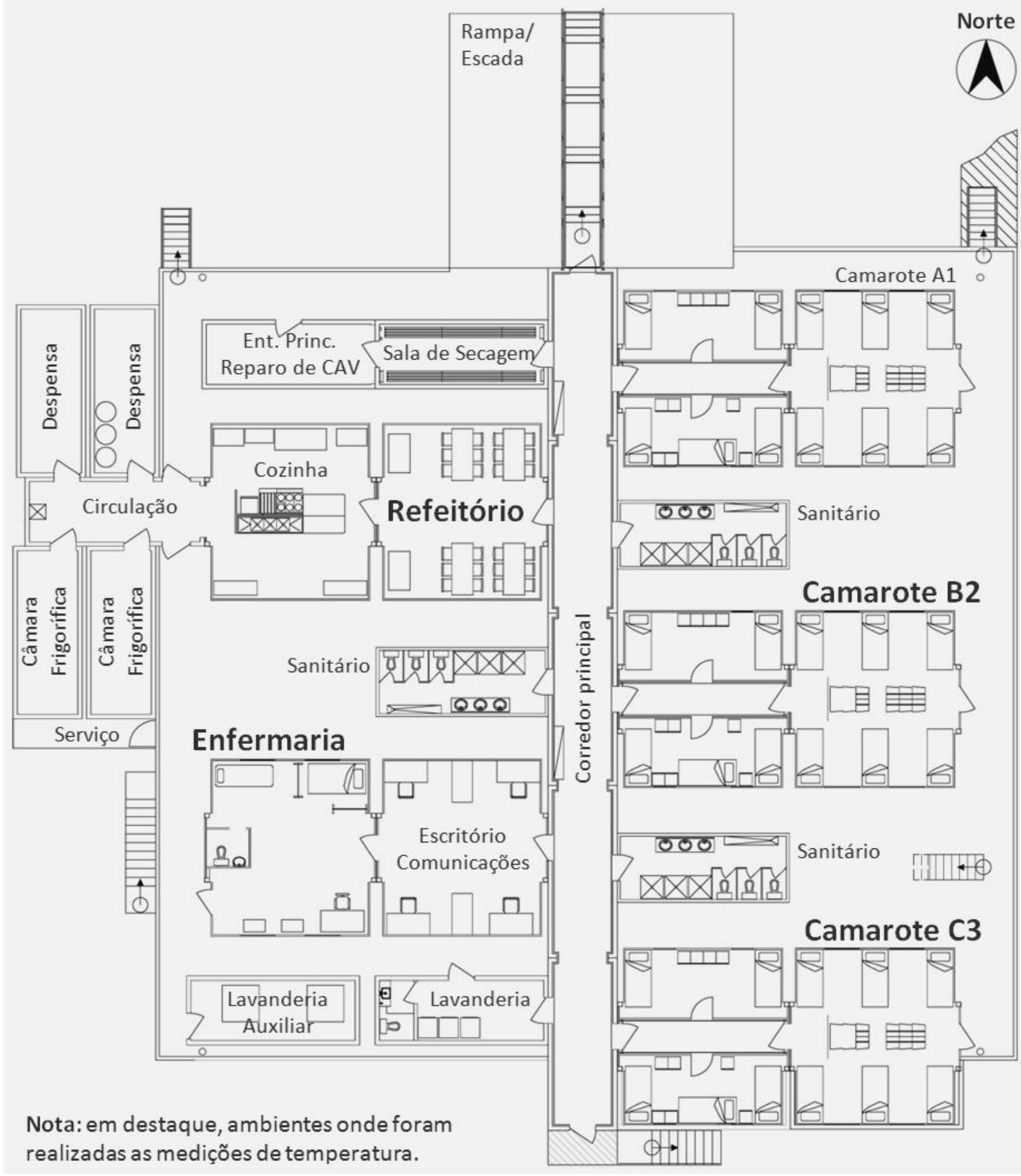

Fonte: adaptada dos acervos da SECIRM e da WCRL. 
Os ambientes selecionados podem ser caracterizados da seguinte forma:

- Camarotes B2 e C3: são ambientes de dormitório, sendo o primeiro localizado na parte central dos MAE, supondo-se ficar mais protegido das intempéries que o segundo, que é localizado na extremidade sudeste, ficando numa condição de maior exposição;

- Enfermaria: por se tratar de um ambiente de recuperação para pessoas com problemas de saúde, ou seja, em estado de maior vulnerabilidade, demanda atenção especial com relação ao conforto térmico e, por estar cercado por outros módulos, é suposto que fique mais protegida das intempéries; e

- Refeitório: trata-se do principal ambiente de estar e de reunião das pessoas, sendo utilizado por todos os usuários e, por estar cercado por outros módulos, assim como a enfermaria, é possível inferir que ele também fique mais protegido das intempéries.

Em cada cômodo foram instalados três aparelhos tipo data logger, modelo HOBO U12-013, da fabricante Onset, que mediram e registraram a temperatura do ar e a temperatura radiante, automaticamente, a cada hora, de 20 de março de 2014 a 11 de março de 2015, ou seja, pela duração de quase um ano completo.

Seguindo-se as recomendações da ISO 7726 (1998), na enfermaria e no refeitório, que são ambientes onde as pessoas ficam sentadas ou deitadas na maior parte do tempo, os aparelhos foram instalados nas alturas de $0,10 \mathrm{~m}, 0,60 \mathrm{~m}$ e 1,10 $\mathrm{m}$ do piso, correspondentes às alturas respectivas do tornozelo, do abdômen e da cabeça de uma pessoa sentada. Por sua vez, nos camarotes, como são utilizados beliches e, com isso, as pessoas ficam deitadas em alturas diferentes, os aparelhos foram instalados nas alturas de $0,10 \mathrm{~m}, 1,10 \mathrm{~m}$ e 1,70 $\mathrm{m}$, correspondentes às alturas das mesmas partes do corpo para uma pessoa de pé, conforme a mesma norma.

\subsection{Verificação da correlação entre a temperatura do ar externa e a interna}

Dados meteorológicos da EACF de março de 2014 a março de 2015 foram disponibilizados pelo Laboratório de Interação Ar-Mar - LIAM, pertencente ao Grupo de Micrometeorologia do Instituto de Astronomia, Geofísica e Ciências Atmosféricas da Universidade de São Paulo. A partir da elaboração de diagramas de dispersão das temperaturas do ar externas, disponibilizada pelo LIAM, e das internas, medidas nos quatro ambientes, foi possível verificar a correlação entre elas, a fim de se avaliar o desempenho da envoltória, juntamente com o sistema de aquecimento dos MAE.

\subsection{Determinação dos períodos de inverno e de verão}

Aplicando-se a metodologia proposta por Akutsu \& Vittorino (1991), foram identificados os meses caracterizados como "mais frios" e "mais quentes", denominados, a título de convenção, como períodos de inverno e de verão, respectivamente. Para isso, foi utilizado o segundo critério indicado pelos autores, como apresentado a seguir:

O período de verão será composto pelos meses que apresentarem média das temperaturas médias mensais acima do valor médio anual mais um desvio padrão. Analogamente, o período de inverno é definido pelos meses que apresentarem média das temperaturas médias mensais abaixo do valor médio anual menos um desvio padrão (AKUTSU e VITTORINO, 1991, p. 218).

Para os cálculos, foram utilizados os dados de climatologia de Ferraz, disponibilizados pelo Centro de Previsão de Tempo e Estudos Climáticos, do INPE (acesso em 06 abr. 2016), que abrangem o período de 1984 a 2013. 


\subsection{Avaliação da adequabilidade da temperatura operativa nos ambientes}

A fim de se verificar a adequabilidade da temperatura operativa nos ambientes, foram gerados boxplots (gráficos de caixa) para cada período, para se observar a distribuição dos resultados, de forma integral, considerando-se sua concentração e variabilidade, comparadas às estabelecidas pela ISO 7730 (2005). Observa-se que a norma considera uma temperatura operativa por volta de $22^{\circ} \mathrm{C}$ como ideal em um ambiente onde se utiliza do sistema de aquecimento, para usuários em atividade sedentária (1,2 met), com um isolamento de vestimenta referente, por exemplo, ao proporcionado pelo uso de uma blusa, com camisa, calça, meias grossas e calçado ( 1,0 clo), e umidade relativa do ar em torno de $40 \%$.

Também foram gerados boxplots para se avaliar as diferenças da temperatura operativa entre horas seguidas nos ambientes, para todo o período de medições, utilizando-se como referência, neste caso, os parâmetros da ASHRAE 55 (2010).

\section{Resultados e discussão}

Os principais resultados, obtidos nas etapas 2 e 4, são apresentados separadamente, nos tópicos a seguir.

\subsection{Dispersão da temperatura do ar externa e interna}

O Gráfico 1 apresenta os resultados de correlação para o refeitório, como exemplo, sendo que também foram elaborados gráficos semelhantes a esse para os demais ambientes.

Percebeu-se que as nuvens de pontos de todos os gráficos foram bem dispersas, sendo que os pontos não se agruparam em torno de nenhuma possível reta diagonal ou parábola de regressão, o que indica que não há correlação entre a temperatura do ar externa e a interna.

Gráfico 1: Diagramas de dispersão para temperatura externa e interna, no refeitório, para as três alturas de medição.

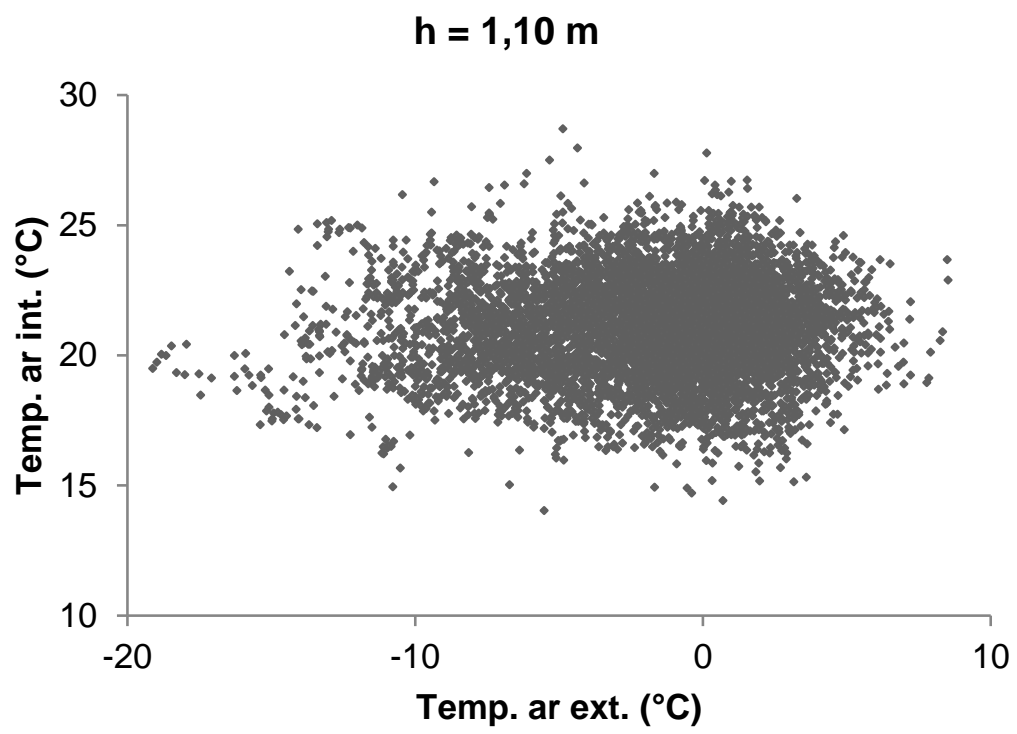



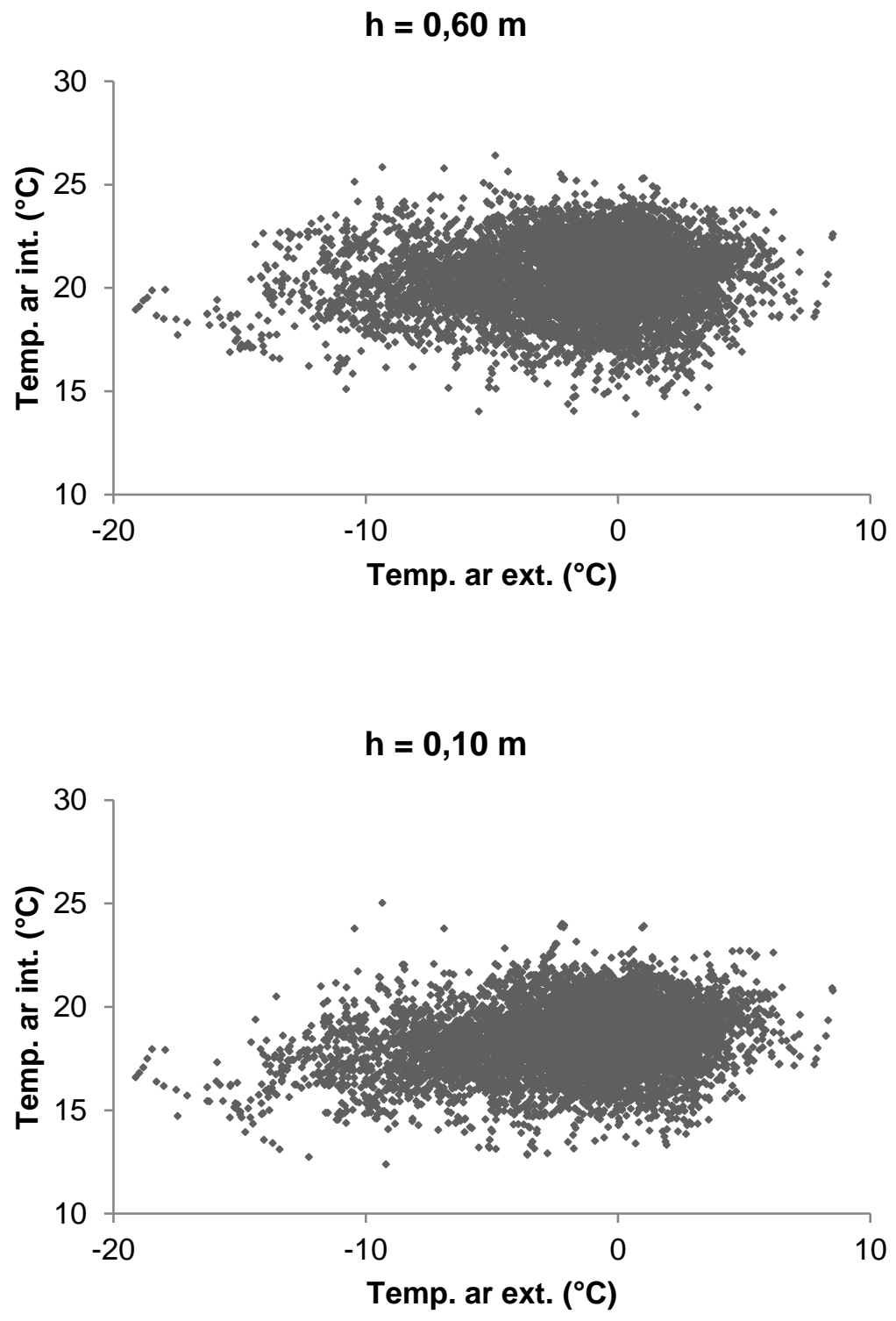

Fonte: Autores.

Com isso, foi possível deduzir que, apesar dos problemas de estanqueidade identificados com as visitas exploratórias e os levantamentos junto aos usuários, apresentados em Autores (2014), a envoltória mantém o ambiente interno termicamente bem isolado do externo, e/ou o sistema de aquecimento é capaz de compensar as diferenças de temperatura.

\subsection{Temperatura operativa nos ambientes frente à ISO 7730:2005}

Foram obtidos resultados de temperatura operativa no camarote $\mathrm{C} 3$, na enfermaria e no refeitório, nas alturas intermediárias, em que foi medida a temperatura radiante, necessária para o cálculo, para todo o período de medições e para os períodos de inverno e verão, determinados com a aplicação do método de Akutsu e Vittorino (1991), conforme apresentado no Quadro 1. 
Quadro 1: Períodos determinados para a avaliação dos MAE e sua abrangência.

\begin{tabular}{ll}
\hline Período & Abrangência \\
\hline Geral & $\begin{array}{l}\text { Todo o período de medições } \\
\text { (registros de 20 de março de 2014, às 19h, } \\
\text { a 11 de março de 2015, às 20h) }\end{array}$ \\
Inverno & $\begin{array}{l}\text { Meses de janeiro e fevereiro completos } \\
\text { (registros de 2015) }\end{array}$ \\
Verão & $\begin{array}{l}\text { Meses de junho a agosto completos } \\
\text { (registros de 2014) }\end{array}$ \\
\hline & \multicolumn{1}{c}{ Fonte: Autores. }
\end{tabular}

Fonte: Autores.

O camarote B2 não foi considerado na avaliação da temperatura operativa devido a falhas não solucionadas nas medições da temperatura radiante, que comprometeram a confiabilidade para a análise do ambiente.

A temperatura operativa foi calculada como a média da temperatura do ar e da temperatura radiante, conforme recomendações da ISO 7726 (1998) para situações em que a velocidade do ar é inferior a 0,2 $\mathrm{m} / \mathrm{s}$ ou em que a diferença entre as duas temperaturas medidas é inferior a $4^{\circ} \mathrm{C}$.

Observa-se que, para a comparação com a ISO 7730 (2005), foram considerados os coeficientes determinados para o período que a norma denomina como de inverno - diferente dos períodos determinados pelo método de Akutsu e Vittorino (1991) -, em que se utiliza do sistema de aquecimento, sendo que nos MAE o sistema de aquecimento é utilizado durante todo o ano.

O Gráfico 2 apresenta os resultados do refeitório para todo o período de medições, como exemplo.

No refeitório, a concentração dos resultados - considerando-se os $50 \%$ deles em torno da mediana (representados pelas caixas dos boxplots no Gráfico 2) - foi além dos limites para a categoria C da ISO 7730 (2005) em algumas horas, para todo o período de medições e, principalmente, para o período de verão, mas pôde se enquadrar nessa mesma categoria no período de inverno.

É possível que a queda da concentração dos resultados observada no refeitório no período de verão, para abaixo dos limites da categoria $\mathrm{C}$, se deva ao fato de que durante esse período há mais pessoas nos MAE e, com isso, há mais perdas de calor por abertura de portas.

Observou-se, ainda, que o comportamento da temperatura no refeitório é influenciado pela forma com que a cozinha é utilizada, sendo um ambiente adjacente ao outro. Após o café da manhã, há uma grande movimentação de usuários de um ambiente para outro, abrindo-se as portas e causando perda de calor, sendo que, de 08 às 10 horas, não há atividade de cozimento - que poderia aquecer o ambiente. Destaca-se que essas observações são bastante coerentes com os resultados de todo o período de medições e do período de verão. Além disso, quando a cozinha começa a funcionar para o almoço, o ambiente tende a esquentar mais do que o resfriamento causado pelo abrir e fechar de portas. Já de madrugada, não há movimentação de usuários.

$\mathrm{Na}$ enfermaria, em geral a concentração dos resultados ficou acima da apresentada para o refeitório, e se enquadrou na categoria $C$ para todo o período de medições e para o período de verão, e na categoria B para o período de inverno. 
Gráfico 2: Temperatura operativa por hora no refeitório para todo o período de medições (20/03/2014, às 19h, a $11 / 03 / 2015$, às 20h) e categorias de conforto da ISO 7730 (2005) para período em que se utiliza do sistema de aquecimento (isolamento de vestimenta $=1,0 \mathrm{clo}$; taxa metabólica =1,2 met; umidade relativa $=40 \%$ ).

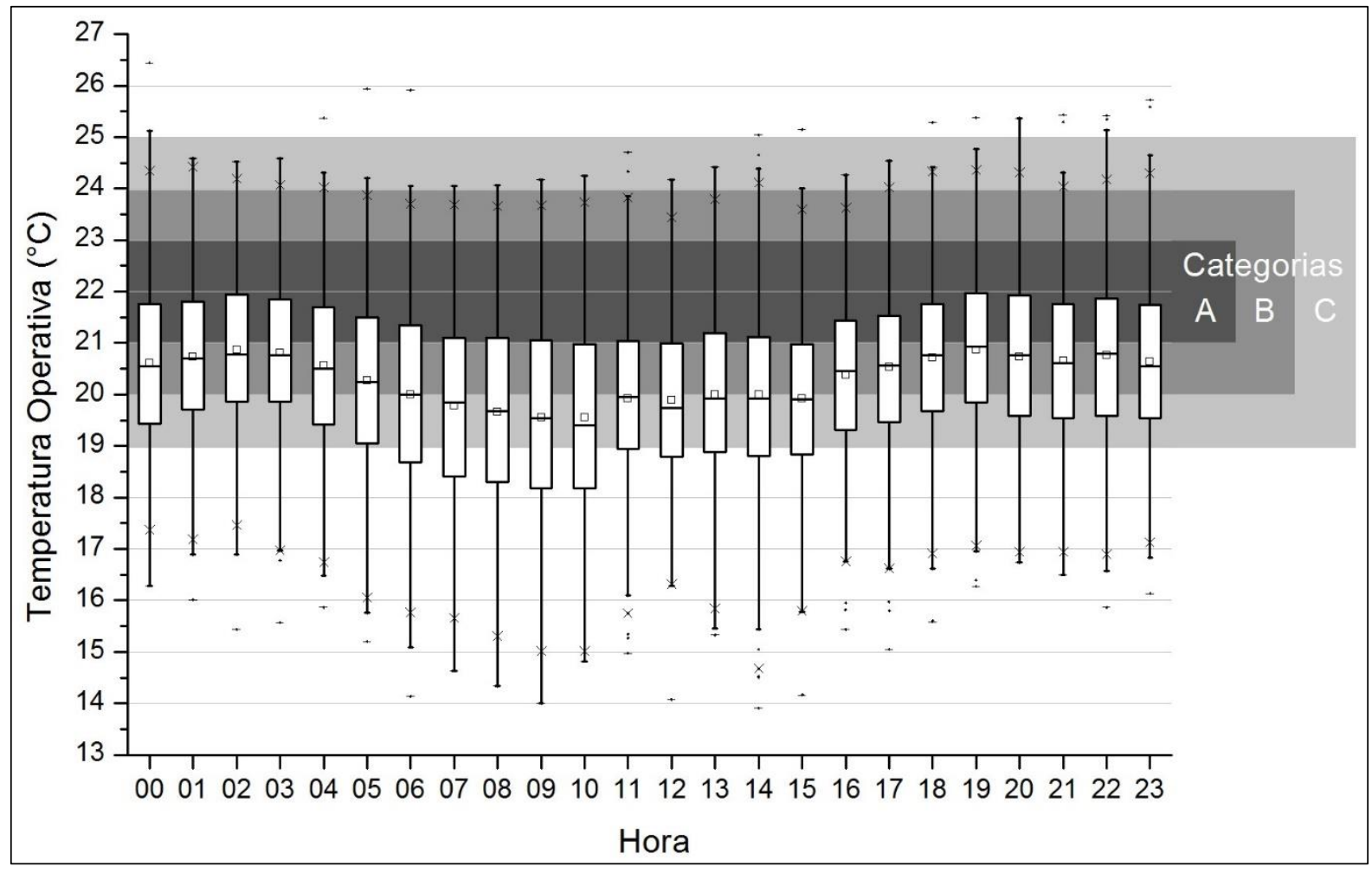

Fonte: Autores.

O fato de a enfermaria ser o ambiente com menor uso pode ter contribuído para se manterem as concentrações de temperatura dentro de uma faixa aceitável, sendo que com o menor trânsito de usuários há menos abertura de portas, preservando-se o calor no recinto.

Por outro lado, no período de verão, além das maiores amplitudes, em várias horas do dia, as concentrações dos resultados na enfermaria abrangeram temperaturas inferiores às abrangidas pelas concentrações dos outros períodos. Isso pode ter sido ocasionado pelo fato de que, por haver mais pessoas nos MAE durante esse período, pode ter acontecido uma maior movimentação de usuários no local, havendo mais trocas e perdas de calor por abertura de portas.

No camarote C3, a concentração dos resultados foi além dos limites para a categoria $\mathrm{C}$, em grande parte das horas, para todo o período de medições e para o período de inverno.

Nestes períodos, houve uma evidente queda da temperatura a partir das 07 horas da manhã, que é o horário em que os usuários costumam acordar, começando a se movimentar de um cômodo para outro, abrindo portas e, consequentemente, permitindo as trocas de calor entre os ambientes. Provavelmente, ao abrir das portas, há perda de calor do camarote C3 para o corredor de acesso, que é menos aquecido.

Também é possível que as concentrações com menores temperaturas tenham ficado ao redor do meiodia, geralmente, pois os usuários não costumam permanecer nos camarotes nesses horários, não havendo um controle da temperatura.

Em contrapartida, no período de verão, a concentração dos resultados do camarote $C 3$ se enquadrou na categoria $\mathrm{A}$, em algumas horas, e na categoria $\mathrm{B}$, em outras. Como há um maior número de usuários nos MAE, neste período, os camarotes acabam sendo mais utilizados durante o dia, o que pode garantir um maior controle da temperatura. 
De forma geral, é provável que com pequenos ajustes o ambiente térmico dos MAE poderia ser classificado como de categoria C, da ISO 7730 (2005).

Adicionalmente, o Gráfico 3 apresenta as diferenças da temperatura operativa entre horas seguidas, para todo o período de medições, nos ambientes avaliados.

Percebe-se que a enfermaria foi o ambiente em que as diferenças da temperatura operativa entre horas seguidas foram menores - em geral abaixo de $0,25^{\circ} \mathrm{C}$-, seguida do refeitório - em sua maioria abaixo de $0,75^{\circ} \mathrm{C}$-, sendo que o camarote $\mathrm{C} 3$ foi o que apresentou as maiores mudanças, com concentração abaixo de $1,5^{\circ} \mathrm{C}$. É possível que essas diferenças tenham ocorrido pelas mesmas razões apresentadas anteriormente para cada ambiente, relativas principalmente ao seu uso e à abertura de portas, com trocas de calor.

Gráfico 3: Diferenças de temperatura operativa entre horas seguidas nos ambientes para todo o período de medições (20/03/2014, às 19h, a 11/03/2015, às 20h).

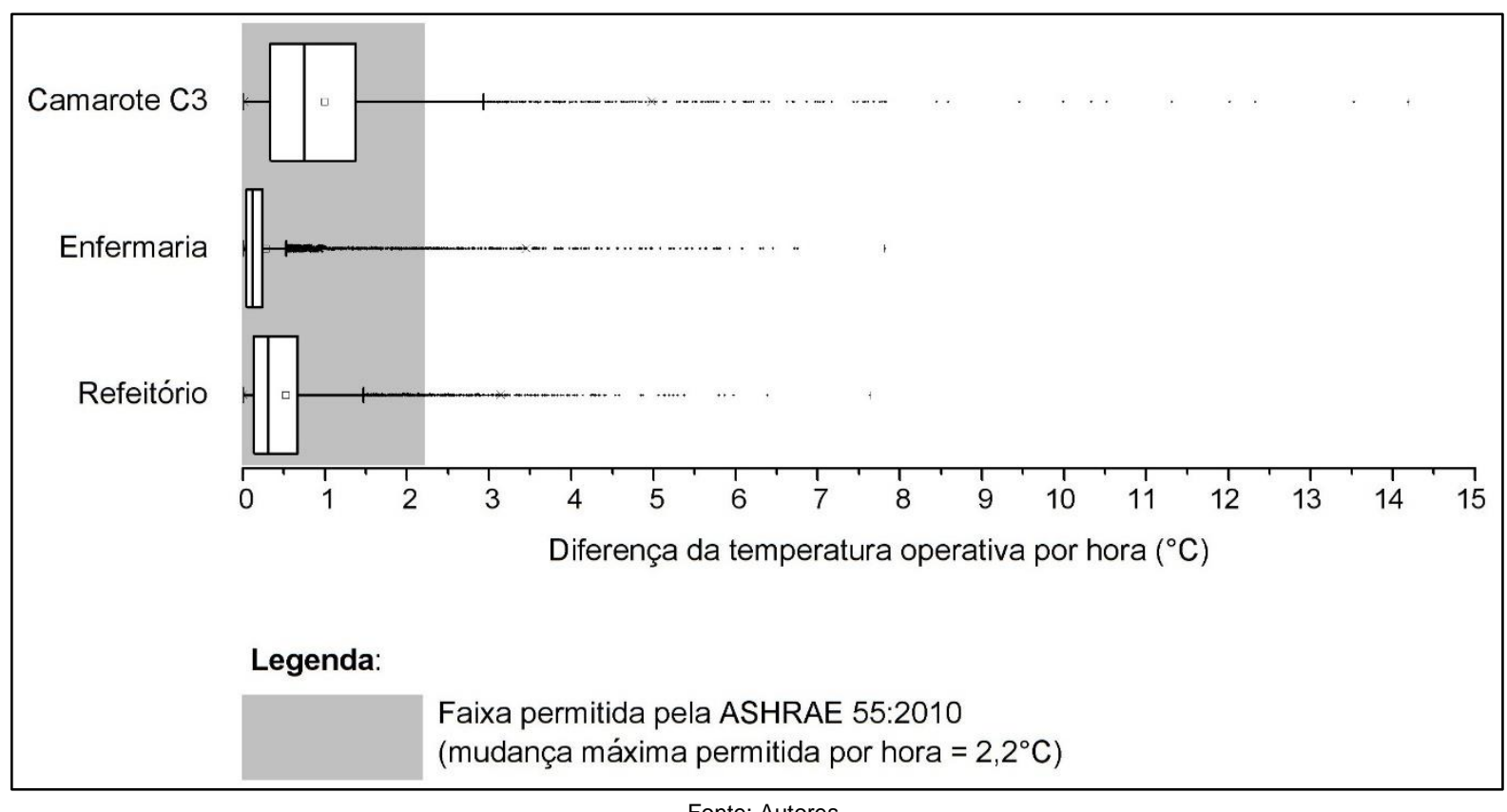

Fonte: Autores.

No camarote $\mathrm{C} 3,8,90 \%$ destes resultados foram superiores à mudança máxima de temperatura operativa permitida por hora pela ASHRAE 55 (2010), isto é, de $2,2^{\circ} \mathrm{C}$, ao passo que na enfermaria esse coeficiente foi de apenas $2,36 \%$, enquanto no refeitório o mesmo foi de $3,17 \%$.

Tratando-se de uma edificação provisória em uma região onde as condições climáticas são extremas, com mudanças bruscas frequentes, entende-se que esses coeficientes são baixos e satisfatórios para seu desempenho e o conforto dos usuários.

\section{Conclusão}

Como conclusão, alguns dos principais resultados obtidos indicaram que não houve correlação entre as temperaturas internas e externas, considerando-se o período de praticamente um ano de medições, apesar dos problemas de estanqueidade identificados com o levantamento junto aos usuários e as visitas ao local. Com isso, foi possível se deduzir que a envoltória mantém o ambiente interno termicamente bem isolado do externo e/ou que o sistema de aquecimento é capaz de compensar as diferenças de temperatura.

Através da análise dos resultados de temperatura operativa nos ambientes, foi possível concluir que, de forma geral, o ambiente térmico dos MAE poderia ser classificado como de categoria $\mathrm{C}$, conforme os 
parâmetros da ISO 7730:2005, que foi a principal norma de referência adotada para a avaliação.

Quanto às diferenças de temperatura entre horas seguidas nos ambientes, tratando-se de uma edificação provisória em uma região onde as condições climáticas são extremas, com mudanças bruscas e frequentes, os coeficientes obtidos foram considerados baixos e satisfatórios para seu desempenho e o conforto dos usuários.

\section{Agradecimentos}

Ao Programa Antártico Brasileiro - PROANTAR, pela compra dos equipamentos de medição; ao Cmte. Eduardo da C. Pereira Júnior e sua equipe, pela colaboração com sua instalação e monitoramento, além das informações fornecidas; e aos Grupos Base das Operações Antárticas, pelo apoio durante as visitas nos MAE.

Ao LIAM, pela disponibilização dos dados meteorológicos solicitados da EACF.

À Coordenação de Aperfeiçoamento de Pessoal de Nível Superior - CAPES e à Fundação de Amparo à Pesquisa e Inovação do Espírito Santo - FAPES, pelo apoio financeiro.

À Prof. ${ }^{a}$ Dra. Edna A. Nico-Rodrigues, à Prof. ${ }^{a}$ Dra. Eliana Zandonade e ao Prof. Dr. João Luiz C. N. da Gama, pelas orientações.

\section{Referências}

ALVAREZ, C. E. de; CASAGRANDE, B.; WOELFFEL, A. B. A adoção da metodologia de Avaliação PósOcupação enquanto instrumento de diagnóstico da Estação Antártica Comandante Ferraz, Brasil: resultados preliminares. In: XV REUNIÓN DE ADMINISTRADORES DE PROGRAMAS ANTÁRTICOS LATINOAMERICANOS - RAPAL, 15., 2004, Guayaquil. Anais... Guayaquil: Programa Antártico Equatoriano, 2004. p. 1-5.

AKUTSU, M; VITTORINO, F. Proposta de procedimentos para o tratamento de dados climáticos. In: ENCONTRO NACIONAL DE NORMALIZAÇÃO LIGADA AO USO RACIONAL DE ENERGIA E AO CONFORTO AMBIENTAL EM EDIFICAÇÕES, 1., 1991, Florianópolis. Anais... Florianópolis: Universidade Federal de Santa Catarina, 1991. p. 213-226.

AMERICAN SOCIETY OF HEATING, REFRIGERATING AND AIR CONDITIONING ENGINEERS. ASHRAE Standard 55: Thermal environmental conditions for human occupancy. Atlanta, 2010.

FANTICELE, F. B. Avaliação de conforto térmico na Estação Antártica Comandante Ferraz. 2011. 118 f. Dissertação (Mestrado em Engenharia Civil) - Programa de Pós-Graduação em Engenharia Civil, Universidade Federal do Espírito Santo, Vitória, 2011.

GUERRA-SANTIN, O.; TWEED, A. C. In-use monitoring of buildings: An overview and classification of evaluation methods. Energy and Buildings, v. 86, p. 176-189, jan. 2015.

INSTITUTO NACIONAL DE PESQUISAS ESPACIAIS - INPE (Brasil). Centro de Previsão de Tempo e Estudos Climáticos. Climatologia de Ferraz. Disponível em: <http://antartica.cptec.inpe.br/>. Acesso em: 06 abr. 2016.

INTERNATIONAL ORGANIZATION FOR STANDARDIZATION. ISO 7726: Ergonomics of the thermal environment - Instruments for measuring physical quantities. Genebra, 1998.

INTERNATIONAL ORGANIZATION FOR STANDARDIZATION. ISO 7730: Ergonomics of the thermal environment - Analytical determination and interpretation of thermal comfort using calculation of the PMV and PPD indices and local thermal comfort criteria. Genebra, 2005. 
MARINHA DO BRASIL. Solicitação de proposta de cotação: Módulos Antárticos Emergenciais (MAE). Brasília, 2012.

$\mathrm{MECH}, \mathrm{K}$. How Hard-Wall Expandable Containers helped Brazil recover from an antarctic disaster. Innovation: Journal of The Association of Professional Engineers and Geoscientists of British Columbia, v. 17, n. 3, p. 20-22, 2013.

ORNSTEIN, S. W.; ROMERO, M de A. Avaliação Pós-Ocupação (APO) do Ambiente Construído. São Paulo: Studio Nobel, 1992.

SECRETARIA DA COMISSÃO INTERMINISTERIAL PARA OS RECURSOS DO MAR - SECIRM.

Programa Antártico Brasileiro - PROANTAR. Disponível em:
<http://www.mar.mil.br/secirm/portugues/proantar.html>. Acesso em: 12 ago. 2015.

SOUZA, J. E. B. de. Brasil na Antártica: 25 Anos de História. São Carlos: Vento Verde Editora, 2008. $167 \mathrm{p}$.

WEATHERHAVEN CANADA RESOURCES LIMITED - WCRL. Apresentação da proposta [para os MAE]. Burnaby, 2012. 